\title{
Políticas de escolarização e governamentalidade nas tramas do capitalismo cognitivo: um diagnóstico preliminar
}

Roberto Rafael Dias da Silval

\begin{abstract}
Resumo
0 presente ensaio pretende constituir um diagnóstico preliminar das políticas de escolarização e governamentalidade produzidas nas tramas políticas e econômicas do estágio atual do desenvolvimento capitalista. Partindo de uma revisão dos modos de constituição das políticas de escolarização produzidas pelo estado moderno, interessa, desde uma inspiração nos estudos foucaultianos produzidos no final da década de 1970, caracterizar as diferentes estratégias reguladoras dos processos de escolarização em massa produzidos desde o século XVIII e diagnosticar os múltiplos deslocamentos nessas pautas políticas na contemporaneidade. A partir de uma leitura sociológica, apresentam-se algumas mudanças nos sentidos educacionais fabricados pela sociedade industrial, na direção de uma educação flexível e interativa. Entende-se que as condições do capitalismo cognitivo, tal como esse cenário tem sido nomeado pelos economistas neomarxistas italianos, sugerem um cenário no qual o conhecimento assume o lugar de vetor das inovações e das dinâmicas produtivas, desestabilizando o modelo da fábrica e imaterializando as relações de trabalho. As políticas de escolarização passam a ser movidas por tecnologias otimizadoras que privilegiam conduzir os sujeitos escolares a estágios elevados de desempenho, assim como propõem a qualificação de suas performances nas tramas do contemporâneo. Tal diagnóstico pode ser ponto de partida para ressignificarmos as pautas investigativas dos estudos críticos em educação.
\end{abstract}

\section{Palavras-chave}

Políticas de escolarização - Governamentalidade - Capitalismo cognitivo. 


\section{Schooling policies and governmentality in the schemes of cognitive capitalism: a preliminary diagnostic}

Roberto Rafael Dias da Silva'

\begin{abstract}
This essay intends to present a preliminary diagnostic of the schooling policies and governmentality produced by the political and economic schemes at the present stage of capitalist development. Based on a review of the modes of constitution of schooling policies produced by the modern state, it becomes of interest, drawing from the Foucauldian studies of the late 1970s, to characterize the different strategies that regulate mass schooling processes created since the 18th century, and to diagnose the multiple shifts that have taken place in contemporary political agendas. From a sociological reading, some of the changes in the educational meanings made by the industrial society are presented, in the direction of a flexible and interactive education. It is understood here that the conditions for cognitive capitalism, such as this scenario has been named by Italian neo-Marxist economists, suggest a scenario in which knowledge assumes the role of a vector of innovations and productive dynamics, destabilizing the model of the industrial plant and dematerializing labor relations. Schooling policies are then driven by optimizing technologies that emphasize conducting the schooling subjects to higher levels of performance, and propose the qualification of their performances within the contemporary schemes. Such diagnostic can be the starting point for a re-signification of research agendas in the critical studies of education.
\end{abstract}

\section{Keywords}

Schooling policies - Governmentality - Cognitive capitalism.
I- Universidade Federal da Fronteira Sul, Erechim, RS, Brazil.

Contact: robertoddsilva@yahoo.com.br 
As múltiplas tensões existentes na relação entre educação e sociedade; métodos de ensino e conteúdos a serem ensinados; currículos escolares e práticas docentes, atravessam a histórica produção das culturas escolares. Percebe-se que vêm ocorrendo modificações, desde a emergência e a consolidação do discurso pedagógico, em diferentes tempos e lugares, até o lugar de defınição dos saberes a serem ensinados.

Desde as corporações de ofício, passando pelas universidades medievais, até a contemporaneidade, o monopólio de definição do que deveria ser traduzido em conhecimento escolar vem recebendo novos agenciamentos, inserindo-se em diferenciadas redes de poder e de saber. Além disso, faz-se possível afirmar que as próprias concepções de estudante, professor ou instituição escolar receberam variações no interior dessa trama histórica.

Importa apontar que, desde a consolidação da modernidade pedagógica, podemos situar o estado como a instância que atribuía aos pressupostos pedagógicos o respaldo necessário para sua atuação (NARODOWSKI, BRAILOVSKI, 2006). Assim, dessa articulação entre pedagogia e estado moderno, fez-se possível notar uma conotação urbanizadora e civilizadora aos incipientes sistemas escolares estatais.

Tanto na Europa quanto na América Latina, o final do século XIX marcou a emergência de um processo de consolidação da função educadora dos estados (CAMBI, 1999; NARODOWSKI, BRAILOVSKI, 2006), fato esse decorrente de sua capacidade financiadora e de seus novos desafios ligados ao controle estatal de suas populações.

Na organização dos Estados Nacionais, a infância e sua educação escolar se convertem claramente em uma questão de Estado, e na ficção moderna a escola e o Estado aparecem articulados, apoiados um ao outro. E assim, a partir da organização dos sistemas educativos nacionais, fenômeno recente se se consideram os longos tempos históricos, os caminhos da escola e do Estado tiveram que andar juntos (NARODOWSKI; BRAILOVSKI, 2006, p. 64).

A partir dessas condições, a escola moderna e suas promessas foram reposicionadas desde as disposições e capacidades do estado moderno. Segundo Narodowski e Brailovski (2006), ocorria uma aproximação articulada não apenas pelas condições de financiamento do estado, mas também por sua capacidade pública de "legitimar uma utopia e de produzir processos massivos de disciplinamento escolar com fortes efeitos homogeneizadores e universalizantes" (NARODOWSKI; BRAILOVSKI, 2006, p. 65).

A escola pública, pelo menos no ocidente, emergiu como uma ferramenta de estado destinada a publicizar o ideário de uma nação, delinear os vínculos identitários de seus frequentadores e projetar crenças e valores para o futuro. A urbanidade, e sua materialização nas reformas das cidades do século XVIII e XIX, tornaram-se um dos grandes ideais da educação financiada pelo estado. 0 estar e o viver nas cidades - a formação de cidadãos - efetivaramse como uma das grandes metanarrativas pedagógicas da modernidade, ideário que ainda sustenta boa parte das pedagogias do nosso tempo (CAMBI, 1999).

Popkewitz assinala que a administração social dos indivíduos, desde a atuação política do estado moderno, não estava circunscrita apenas a práticas ou modelos formais de organização, mas se referia a um tipo de conhecimento "que ordena e disciplina a ação e a participação, isto é, o conhecimento é uma prática de administração social" (POPKEWITZ, 2000, p. 142). Dessa perspectiva, cabia ao estado a possibilidade de estabelecer vínculos entre as necessidades naturais de sua população e as novas demandas da vida democrática.

Correspondia ao Estado dar forma ao indivíduo de maneira que dominasse a mudança mediante a aplicação dos princípios da racionalidade e da razão (POPKEWITZ, 2000, p. 144). 
Seguindo a analítica proposta pelo autor, o problema do governo "inscrevia-se nas disposições e nas capacidades da individualidade" (p. 145).

Uma das novas áreas de intervenção possibilitadas pela consolidação do estado moderno, consequentemente, foram as políticas de escolarização. Tais políticas permitiam que o estado operasse tanto na vida pública das sociedades quanto na liberdade e na individualidade dos indivíduos. Popkewitz (2000) nomeia essa modalidade de prática governamental como "racionalização populacional".

A escolarização maciça ficou enquadrada nesse movimento encaminhado para administrar socialmente o crescimento, o desenvolvimento e a evolução da sociedade. A escola, como projeto de reforma, devia ocupar-se dos processos de socialização a partir dos quais a criança podia chegar a ser o adulto que agisse de maneira responsável em novos contextos de governo da modernidade. A escola representava noções liberais sobre o indivíduo disciplinado que agia responsavelmente e, assim, uniu-se ao trabalho de construir a criança que havia de ser civilizada como o novo cidadão, a práticas de administração social que faziam uso de uma razão populacional para domesticar contingências históricas em forma de política social, administração social e razão científica (POPKEWITZ, 2000, p. 145-146).

Assim, as políticas de escolarização foram produzidas historicamente tomando como alvo e objetivo privilegiados a constituição de uma população com novas características, mais apropriadas ao nascente estado moderno, fortemente ancorado nos ideais do liberalismo político. As estratégias de formação dos sujeitos privilegiavam a formação desse novo cidadão. A contemporaneidade, entretanto, desde a emergência das condições do novo capitalismo (SENNETT, 2008), intensificou suas ações políticas de escolarização projetando indivíduos capazes "de evoluir numa cultura e numa economia globais” (POPKEWITZ, 2000).

Para o tratamento analítico dessas questões, os trabalhos do filósofo francês Michel Foucault produzidos no final da década de 1970 acerca do conceito de governamentalidade, trouxeram novas possibilidades de investigação. Importantes estudos no âmbito das políticas de escolarização têm tomado como ferramenta analítica o referido conceito (VEIGA-NETO, 2006; NOGUERA, 2009; Ó, 2009; FIMYAR, 2009).

Em aproximação a esse produtivo campo, o uso da governamentalidade de que lançaremos mão para este ensaio aproxima-se daquilo que Noguera (2009) aponta como noção metodológica. Conforme o pesquisador colombiano, "uma noção metodológica é uma ferramenta para pensar, um instrumento para operar sobre um problema” (NOGUERA, 2009, p. 23). Dessa forma, o conceito de governamentalidade é uma ferramenta desenvolvida por Foucault que serviu para "o desenvolvimento de sua atividade de investigação e ensino” (NOGUERA, 2009, p. 23). Assim sendo, são os sentidos (e não as definições) atribuídos a esse conceito foucaultiano que privilegiaremos nesta composição analítica.

Para o estudo da governamentalidade e da biopolítica (FOUCAULT, 2008a; FOUCAULT, 2008b), vale destacar que, desde o curso de 1978, aos poucos o pensamento foucaultiano foi se deslocando das concepções de poder e se aproximando do conceito de governo. 0 conceito de governo fez-se mais operatório do ponto de vista da produção das análises, uma vez que partia da premissa do poder em ação. Tal como sugeriu Foucault, o governo toma como campo de intervenção a condução das condutas ou, ainda, o modo como somos conduzidos e nos conduzimos. Assim, essa noção implica uma pluralidade de objetos e de fins pretendidos. Em uma importante sistematização, Dean (1999) posiciona o governo como "realização efetuada no plural".

Governo é qualquer atividade mais ou menos racional e calculada, realizada por uma multiplicidade de autoridades e agências, 
que empregam uma variedade de técnicas e formas de conhecimento, que busca moldar a conduta lidando com nossos desejos, aspirações, interesses e crenças, para fins definitivos, mas inconstantes e com um conjunto diverso de consequências, efeitos e resultados relativamente imprevisíveis (DEAN, 1999, p. 11).

Governar, então, implicaria conduzir a conduta dos diferentes indivíduos. A partir dessa abordagem, a noção de governo é ampliada, não permanecendo exclusivamente nas diferentes modalidades de autoridade exercidas sobre os outros, mas incluindo também a nós mesmos. Ao analisarmos tais formas de condução, podemos tomar como objeto

[...] aquelas que tentam moldar, esculpir, mobilizar e lidar com escolhas, desejos, aspirações, necessidades, vontades e estilos de vida de indivíduos e grupos. (DEAN, 1999, p. 12)

Entendemos que empreender essas possibilidades de estudo permite estabelecer uma analitica de governo. Segundo os apontamentos de Veiga-Neto (2006), falar em analítica implica "examinar e analisar as práticas concretas, em sua 'microscopicidade', em sua especificidade" (VEIGA-NETO, 2006, p. 2).

Diferentes campos das ciências sociais têm se preocupado com a dimensão coletiva do pensamento. Segundo Dean (1999, p. 18-19, grifos do autor):

Os estudos de governamentalidade, no entanto, estão mais preocupados em saber como o pensamento funciona no cerne de nossas formas organizadas de fazer as coisas, nossos regimes de práticas e com nossas ambições e efeitos.

Assim, essa configuração de análise está preocupada em estudar os meios pelos quais as condutas dos diferentes sujeitos são moldadas em determinadas condições sociais. A perspectiva analítica proposta por pelo autor pode ser nomeada como analitica de governo, na medida em que se trata de:

[...] um tipo de estudo preocupado com uma análise das condições específicas para determinadas entidades emergirem, existirem e mudarem. (DEAN, 1999, p. 20)

Essa abordagem não posiciona as práticas de governo sob arranjos de modelos idealizados de poder, nem mesmo as posiciona como efeitos ou produtos de contradições ou hegemonias. Uma analítica de governo "examina as condições nas quais se formam, são mantidos e transformados os regimes de práticas" (DEAN, 1999, p. 21). 0 autor, de forma objetiva, mas não simplificada, afirma que tais regimes "são simplesmente conjuntos razoavelmente coerentes de empreender tarefas” (DEAN, 1999, p. 21). Notamos, então, o caráter pragmático dessa modalidade de análise.

A tarefa não compreende descrição empírica de como várias pessoas ou agentes em posição de autoridade governam. A analítica de governo não é uma "sociologia da regência" se o objeto deste for simples relações correntes de autoridade e dominação. Em vez disso, trata-se de um estudo das práticas organizadas através das quais somos governados e governamos a nós mesmos, o que chamaremos aqui de regimes de práticas ou regimes de governo. Tais regimes implicam, no entanto, práticas de produção da verdade e do conhecimento, compreendem múltiplas formas de racionalidade prática, técnica e calculante, e são submetidos a programas de sua reforma. É importante compreendermos que os regimes de práticas existem num meio composto de mentalidades de regência, sem serem redutíveis a tal meio (DEAN, 1999. p. 1819, grifos do autor). 
Dessa forma, ao revisarmos a constituição histórica das políticas de escolarização, faz-se possível observar os modos pelos quais os regimes de governo operam na produção da verdade e do conhecimento que perfazem tais políticas. Compreender as estratégias políticas mobilizadas no interior das políticas de escolarização apresenta-se como um dos mais instigantes desafios para o estudo das políticas contemporâneas.

A seguir, examinaremos algumas dessas racionalidades operantes nas políticas de escolarização produzidas no cenário de transição do capitalismo industrial ao pós-industrial, sobretudo pela leitura proposta desde o conceito de capitalismo cognitivo. Destacamos que nossa intenção não estará em produzir modelos analíticos universalizantes que tenderiam a impor um predomínio de dimensões sociológicas sobre outras de caráter pedagógico. 0 que nos interessa é produzir um diagnóstico preliminar que instrumentalize e potencialize nossos estudos no campo educacional.

\section{Educação e capitalismo cognitivo: um diagnóstico crítico}

0 capitalismo industrial marcou o desenvolvimento econômico e social das sociedades ocidentais durante o século XX (CASTEL, 2004; 2009). Os modos como as sociedades e os sujeitos planejavam seus desenvolvimentos eram marcados pela estabilidade e pelo planejamento a longo prazo, ao mesmo tempo em que as instituições em geral (fossem as escolas ou as empresas, por exemplo) exerciam funções ligadas à disciplinarização. A questão social do século XX, como bem expressou o sociólogo Robert Castel (2009), constituía-se na ocupação do tempo e na distribuição do espaço dos grandes contingentes da população.

Entretanto, desde o final daquele século, alguns deslocamentos significativos ocorreriam nos modos de vida, na administração das coletividades ou mesmo nos planejamentos pessoais e institucionais em relação ao futuro. Não mais as condições disciplinares da sociedade industrial, descritas em profundidade por autores como Michel Foucault (1989), regulariam a vida social. Outras configurações sociais, outros modos de relacionamento com o saber e o poder passaram a emergir nessas sociedades. À medida que valores como a flexibilidade ou a inovação permanente (SENNETT, 2001; 2008) começaram a deslocar os modos clássicos de organização moderna (fordista) do mundo, pequenos sinais de uma nova organização capitalista passaram a adquirir sentido. Como metáfora a esse conjunto de modificações, o sociólogo Richard Sennett argumenta, servindo-se inicialmente de uma expressão weberiana, que a sociedade não mais se organizava como uma "jaula de ferro", mas como um "aparelho de MP3" (SENNETT, 2008, p. 49).

Conforme a descrição de Sennett (2008), durante o grande desenvolvimento capitalista, ocorrido entre os anos de 1860 e 1970, as sociedades e as empresas aprenderam a movimentar-se sob regimes de permanentes crescimentos; com isso, desenvolveram "a arte da estabilidade, assegurando a estabilidade dos negócios e aumentando o número de empregados" (SENNETT, 2008, p. 27). No decorrer desse longo período, desse amplo crescimento, ainda segundo a descrição do sociólogo, não foram as estratégias de mercado que regeram esse processo - "o papel mais importante foi desempenhado pela maneira como os negócios passaram a ser organizados" (SENNETT, 2008, p. 27), ou seja, o desenvolvimento capitalista do século XX desenvolveu-se e consolidou-se com o uso de "modelos militares de organização” (SENNETT, 2008, p. 27).

Como metáfora desse tempo, Sennett (2008) utiliza a jaula de ferro weberiana, uma vez que foi o sociólogo alemão um dos precursores da análise de um capitalismo militarizado. Esse capitalismo industrial emergia por uma política de estabilidade e planejamentos de longo prazo em suas diferentes instituições, visto que objetivava produzir ações disciplinares sobre o conjunto da sociedade. 
Por mais pobre que seja, o trabalhador que sabe que ocupa uma posição bem estabelecida estará menos propenso a se revoltar que aquele que não tem uma noção clara de sua posição na sociedade. Eram estes os fundamentos da política do capitalismo social (SENNETT, 2008, p. 28).

$\mathrm{Na}$ política do capitalismo social, o tempo constituiu-se como um conceito central, "um tempo de longo prazo, cumulativo e sobretudo previsível" (SENNETT, 2008, p. 29). 0 controle do tempo permitia ações de regulação tanto sobre os sujeitos trabalhadores quanto sobre as instituições. A ideia de um tempo racionalizado atribuía a ambos a possibilidade de uma narrativa estável e contínua. Fezse possível que esses espaços apresentassem mudanças significativas: aos trabalhadores, as carreiras poderiam ser planejadas ao longo de um grande período, graças à estabilidade; as empresas poderiam estabelecer estratégias de produção disciplinarizadas e potencializar suas estratégias de acumulação.

Ainda conforme a descrição de Sennett (2008), a divisão social do trabalho, em especial através dos modelos taylorista e fordista, emerge em conexão com a configuração militarizada do capitalismo. Seguindo uma abordagem weberiana, o sociólogo entende que, da mesma forma que um exército em um campo de batalha, "um negócio bem gerido devia ser capaz de sobreviver a movimentos bruscos de expansão e retração do mercado" (SENNETT, 2008, p. 33). Acerca dessa divisão do trabalho, é a fábrica de alfinetes descrita por Adam Smith o seu paradigma explicativo. Um capitalismo industrial disciplinarizado, com competição e efıciência, faria do sistema de produção uma grande maquinaria.

0 modelo smithiano explorava as maneiras de desdobrar uma tarefa complexa para a eficiente produção de uma carroça ou de um queijo. A medida da eficiência estava pura e simplesmente no grau em que alguma coisa podia ser produzida com rapidez, mas o verdadeiro teste da produção smithiana estava no mercado - seria possivel produzir mais depressa que os concorrentes muitas coisas que outras pessoas quisessem comprar? Embora os exércitos funcionem pela divisão do trabalho, Weber deu-se conta de que a competição e a eficiência assumem características diferentes na vida militar (SENNETT, 2008, p. 33).

Com esse arranjo do capitalismo industrial do século XX, marcado por produção disciplinarizada, estabilidade e planejamento de longo prazo (para os sujeitos e as instituições), é que Sennett revitaliza a metáfora weberiana da jaula de ferro. Tal conceito pressupõe organizações com funções fixas e preestabelecidas, marcadas pela disciplina como estratégia de produção e subjetivação. Sob a égide da nomeada jaula de ferro, o estado fez-se burocrático e previdente. Os benefícios desse estado, como a educação e a saúde, eram considerados como direitos universais e movimentados por uma estrutura burocrática. "0 sistema focalizava cada vez mais a estabilidade e a autopreservação institucionais, e não a efetiva provisão de cuidados" (SENNETT, 2008, p. 37).

Em um estado que, conforme Sennett, visava à sua estabilidade e à autopreservação institucional, os sistemas de escolarização consolidariam suas premissas de universalidade e gratuidade (NARODOWSKI, 1999). Em um jogo potente de relações de saber-poder, a escola moderna, com sua disciplina no eixo do corpo e dos saberes (FOUCAULT, 1989), adquiriu o status de principal instituição a serviço do modelo civilizatório da sociedade industrial. Diferentemente de outras instituições sociais, como as da vida religiosa, por exemplo, nas escolas

[...] já não se tratava de preparar os internos para a vida eterna senão de discipliná-los e educá-los para produzir bons súditos e bons cidadãos na vida terrena. (ALVAREZ-URIA, 2002, p. 135). 
A instituição escolar, segundo a argumentação de Alvarez-Uria (2002), funcionou como uma grande maquinaria mobilizadora do espírito do capitalismo gestado e consolidado no transcorrer do século XX ou, segundo Hoskin, citado por Veiga-Neto (2005), serviu como uma dobradiça entre o poder e o saber.

Sob essa lógica disciplinar, marca do capitalismo industrial do referido período, as pedagogias eram desencadeadas como estratégias políticas operadas sobre os tempos e os espaços dos sujeitos e das instituições. Os corpos e os saberes eram distribuídos no tempo e no espaço de maneira a manter e a garantir a produtividade coletiva.

Os indivíduos hão de estar vigiados e localizados permanentemente para evitar encontros perigosos e comunicações inúteis, se de fato se quer favorecer exclusivamente as relações úteis e produtivas. (VARELA, 2002, p. 82)

A classificação e a distribuição dos sujeitos escolares, de acordo com seu rendimento ou sua conduta, é um conhecido exemplo do modo como as pedagogias disciplinares regulavam os espaços.

No que se refere aos tempos, essas pedagogias também mobilizavam significativas inovações.

A nova concepção do tempo exige organizar as atividades de acordo com um esquema de séries múltiplas, progressivas e de complexidade crescente. Organiza distintos niveis separados por provas graduais, que correspondem a etapas de aprendizagem e que compreendem exercícios de dificuldade cada vez maior. Rompe-se assim com um ensino no qual o tempo era concebido globalmente e a aprendizagem sancionada com uma única prova. Essa nova forma de perceber e organizar o espaço e o tempo permite um controle detalhado do processo de aprendizagem, permite o controle de todos e de cada um dos alunos, faz com que o espaço escolar funcione como uma máquina de aprender e, ao mesmo tempo, possibilita a intervenção do mestre em qualquer momento para premiar ou castigar e, sobretudo, para corrigir e normalizar (VARELA, 2002, p. 84).

Outro espaço em que se visibiliza o diagrama de forças da sociedade industrial é a fábrica; da mesma forma que as instituições escolares acima descritas, também toma a disciplina como eixo de ação. Interessava produtivamente a esse arranjo o desenvolvimento de corpos dóceis e úteis, tal como mostra a significativa analítica foucaultiana. Em outras palavras, conforme argumenta o sociólogo italiano Maurizio Lazzarato (2006, p. 86),

0 trabalho constituía, ao mesmo tempo, a substância e a medida da planificação. 0 trabalho se revelou o meio mais eficaz de regulação do conjunto da sociedade.

Ampliando a argumentação, pode-se pensar que o século XX tornou visível uma relação entre sujeito e trabalho, mas, ao mesmo tempo, mobilizou uma racionalidade política que se tornou uma "potência reguladora" (LAZZARATO, 2006, p. 92).

Desejando sujeitos cada vez mais disciplinados e produtivos, o capitalismo industrial "insere-se na esfera da reprodução, está preconcebido e atende a um padrão tecnológico e organizacional estruturado de antemão" (SANSON, 2009, p. 207). Nessa lógica de reprodução, os saberes dos operários são invisibilizados, predominando ações repetitivas, rotineiras e preconcebidas. É central a essa concepção o conceito de força de trabalho, visto que o esforço que é interessante à fábrica é o dispêndio de energia e de tempo gasto. Logo, é possível evidenciar que, sob esse arranjo, a disciplina é uma das principais estratégias, visibilizada não apenas nos sistemas escolares, mas também na fábrica enquanto paradigma institucional. 
0 final do século XX apresentou um conjunto de importantes deslocamentos nos modos de pensar e viver a sociedade industrial. Um dos primeiros autores que destacaram esse processo foi o sociólogo Daniel Bell (1977). Ao tratar desse período, o qual nomeia de novo capitalismo, Richard Sennett apresenta três condições que possibilitaram essas modificações. A primeira condição seria a "mudança do poder gerencial para o acionário" (SENNETT, 2008, p. 41) nas grandes empresas, isto é, a estrutura das empresas passa a ser conduzida segundo o regime dos investidores. Não mais uma burocracia controla o funcionamento das grandes indústrias, mas, com a globalização, fluxos de capital de diversas ordens dirigem as decisões. A segunda condição refere-se ao tempo dos investimentos.

Os investidores dotados de novo poder queriam resultados a curto prazo, e não a longo prazo. Constituíam o contingente do 'capital impaciente', na formulação de Bennett Harrison. (SENNETT, 2008, p. 43)

Sob a lógica do capital impaciente, as empresas demonstravam êxito apresentando "sinais de mudança e flexibilidade internas, dando pinta de empresa dinâmica" (SENNETT, 2008, p. 43). A terceira condição é a emergência das novas tecnologias da comunicação e da informação. Para um capital movido por investidores que objetivam o curto prazo, o fato de as comunicações tornarem-se instantâneas foi fundamental, ao mesmo tempo em que os processos de automação intensificaram a produção e passaram a exigir uma mão de obra diferente.

Conforme Sennett, a Contemporaneidade estaria deslocando-se da "jaula de ferro weberiana" como princípio explicativo da sociedade industrial. A nova estrutura funcionaria como um tocador de MP3.

A máquina de MP3 pode ser programada para tocar apenas algumas faixas de seu repertório; da mesma forma, a organização flexível pode selecionar e desempenhar a qualquer momento apenas algumas de suas muitas possiveis funções. Na corporação ao velho estilo, em contrapartida, a produção ocorre através de um conjunto preestabelecido de atos; os elos da cadeia são fixos. Num tocador de MP3, o que ouvimos pode ser programado em qualquer sequência. Numa organização flexível, a sequência da produção também pode ser alterada à vontade (SENNETT, 2008, p. 49).

Assim, os sujeitos e as instituições produzidos sob a lógica do MP3 privilegiariam valores como flexibilidade, autonomia, inovação, livre circulação e espírito empreendedor. Essa concepção poderia ser visibilizada tanto na lógica dos processos de educação quanto de produção, por exemplo. Na educação, vê-se a emergência de processos de autonomização e autogerenciamento dos processos, a "era do aprender a aprender” (NARODOWSKI, 1999, p. 32). Na produção, deslocam-se os regimes disciplinares fordistas/tayloristas e emergem os regimes toyotistas da inovação permanente (HARVEY, 2003). Trataremos de cada um desses aspectos separadamente.

Quanto à educação, parece-nos que ocorre um deslocamento do caráter coletivo dos processos escolares para os individuais. Seguindo a abordagem de David Hamilton (2002, p. 187), vê-se na atualidade um revivescimento da aprendizagem, ou seja, o ensino (processo coletivo) perde a centralidade nas relações pedagógicas, em detrimento da aprendizagem (processo individual). Hamilton (2002, p. 90) entende que, sob o movimento das chamadas "economias do futuro, movidas a conhecimento", os processos de escolaridade e empregabilidade passam a convergir. É essa conversão, vinculada à centralidade das aprendizagens individuais, que o pesquisador caracteriza como ponto de partida para o planejamento contemporâneo da educação. Expressões como aprendizagem em rede, cursos personalizados e ênfase nos processos 
povoam as práticas desse tempo; entretanto, segundo Hamilton, um dos aspectos centrais na escolarização da sociedade de aprendizagem é a noção de competência.

Com Hamilton, é possível pensar que a ênfase no conhecimento seria típica do capitalismo industrial, em que a reprodução era o conceito que movia a sociedade disciplinar. Ao mesmo tempo, a noção de competência, mais individualizada e flexível, caracterizaria um tempo em que o sujeito é conduzido, em um processo de inovação permanente, a fazer investimentos em si mesmo, na busca de manter-se ativo no mercado de trabalho (SARAIVA; VEIGA-NETO, 2009; SILVA, 2008; 2011a; 2011b).

Conforme os argumentos de Jódar e Gómez (2007), nas sociedades contemporâneas, a pedagogia adquire uma dimensão otimizadora:

[...] formação permanente e polivalente ao longo de toda a vida como substituta à da escola fechada, do controle contínuo como substituto do exame (JÓDAR; GOMÉZ, 2007, p. 393).

Essa pedagogia otimizadora planeja espaços permanentes de formação, visto que "os sujeitos estão sempre em curso" (p. 393). 0 sujeito educacional assim constituído

[...] deve ser competitivo, adaptável, flexível, mutável, disposto e reformular suas escolhas e auto-responsabilizarse sobre o controle de sua produtividade para aumentar assim sua contribuição à excelência. (JÓDAR; GOMÉZ, 2007, p. 393)

Esses deslizamentos do coletivo ao individual, da reprodução à inovação, também se fazem visíveis nas questões ligadas ao trabalho. 0 capitalismo industrial do século $\mathrm{XX}$, tal como o socialismo, era caracterizado pela planificação (LAZZARATO, 2006). Esse capitalismo, conforme já assinalado, era o meio mais eficaz de regulação da sociedade, uma vez que sua lógica se sustentava na reprodução, em um regime disciplinar. Ainda cabe evidenciar que esses deslocamentos não anulam a representatividade da disciplina nas práticas sociais; antes disso, sofisticam-na, tornando-a mais potente e ampla em seu campo de ação (LAZZARATO, 2006). A contemporaneidade mostra-nos um deslocamento, já evidenciado em Deleuze (1992), que é do trabalho fordista, fabril, para uma nova configuração que não mais toma os limites do espaço e do tempo disciplinares como estratégia, mas flui no jogo heterogêneo do novo capitalismo - a empresa.

Na empresa, esse cenário muda radicalmente. 0 número de empregados é drasticamente reduzido, e o regime de trabalho, bastante heterogêneo: trabalhadores formais, prestadores de serviço, terceirizados, sócios minoritários, etc. Cada um parece constituir-se em um caso particular, com uma forma de contrato, cargas horárias e funções diferenciadas (como os sindicatos). Está-se diante de um trabalho que já não prioriza o corpo e seus movimentos mecânicos, mas a alma e seu poder criativo (SARAIVA; VEIGA-NETO, 2009, p. 190-191).

É a esse tempo em que a alma e seu poder criativo adquirem centralidade nas práticas sociais, seja nos processos educativos, seja na organização do mundo do trabalho, que nesse momento dedicaremos maior atenção. É nesse cenário, por muitos caracterizado como capitalismo cognitivo (CORSANI, 2003; VERCELLONE; NEGRI, 2007), que entendemos que as relações entre conhecimento científico e inovação se tornam fundamentais para a organização e produção das políticas de escolarização brasileiras na última década.

Vale destacar que o interesse não está em fazer um elogio ao capitalismo cognitivo, mas posicioná-lo em um campo de forças em que as tecnologias de saber e de poder estão sendo ressignificadas e produzindo intensos desdobramentos ao campo educacional. 
Conforme assinalaremos na próxima seção, processos como a imaterialização do trabalho (LAZZARATO, 2003) e a produção de conhecimentos por conhecimentos (CORSANI, 2003) alteram os modos pelos quais as sociedades contemporâneas se relacionam com o trabalho, com o conhecimento e consigo mesmas.

\section{O capitalismo cognitivo: outras} políticas de escolarização

Com o conceito de capitalismo cognitivo, designamos então um sistema de acumulação no qual o valor produtivo do trabalho intelectual e imaterial se torna dominante e onde o eixo central da valorização do capital porta diretamente sua expropriação "através da renda" do comum e a transformação do conhecimento em mercadoria. Carlo Vercellone e Antônio Negri

As palavras de Carlo Vercellone e Antônio Negri, escolhidas como epígrafe para esta seção, evidenciam algumas profundas modificações na organização do capitalismo na atualidade. Em especial, imediatamente podem ser destacados os processos de imaterialização do trabalho, o deslocamento da reprodução para a inovação, a produção de conhecimentos por conhecimentos e suas consequentes tecnologias de poder. Salientamos que nossa intenção, ao estabelecer um rápido diagnóstico do que vem sendo nomeado como capitalismo cognitivo, é descrever algumas das condições de possibilidade para a constituição das políticas contemporâneas de escolarização. Em nosso diagnóstico preliminar, objetivamos descrever alguns cenários políticos e econômicos contemporâneos que têm produzido desdobramentos à escola de nosso tempo.

As crises no mundo do trabalho fordista e a emergência de um novo modelo organizativo da produção (pós-fordista e toyotista, dentre outras) têm se constituído como importantes objetos de análises sociais na atualidade (HARVEY, 2003; LYON, 1998). Os processos de formação do trabalhador e de administração dos processos produtivos passam a receber um conjunto de inovações, tendo, em geral, conforme o economista italiano Christian Marazzi (2009a), suas origens vinculadas às fábricas da Toyota no período posterior à Segunda Guerra. Em menos de duas décadas, o ocidente recebeu essas práticas, aliás, em um período de crise interna do regime fordista, tornando-se mais dinâmicos os processos produtivos e abrindo-se possibilidades de inovação permanente nos modos de operar.

A chamada produção enxuta (MARAZZI, 2009a) e as ilhas de produção logo invadiram os regimes produtivos europeus e norte-americanos. A produção enxuta (just-in-time), característica de mercados mais restritos e inovadores, ao opor-se aos modelos fordistas de produção, trazia como grande transformação social, política e econômica o fato de "colocar a comunicação e o fluxo de informações no centro da inovação tecnológico-produtiva" (MARAZZI, 2009a, p. 15). Conforme Marazzi, esse movimento produziu uma notável virada linguística na economia das últimas duas décadas. Diferentemente dos modelos fordistas, nos quais imperava o regime da reprodução e da disciplina (o é proibido falar), nos processos just-in-time a comunicação alimenta o processo produtivo.

Compreende-se aqui como a comunicação e sua organização produtiva enquanto fluxo de informações se tornaram tão importantes quanto a energia elétrica na época da produção mecânica. De fato, a comunicação lubrifica todo o processo produtivo, de uma ponta à outra, da produção à distribuição-venda de mercadorias e ao retorno (MARAZZI, 2009a, p.16).

Com essa nova forma de organizar a produção, a comunicação tem um valor diretamente produtivo. Enquanto no fordismo a mão de obra era especializada e parcelar (MARAZZI, 2009a, p. 18), com funções estáveis e preestabelecidas, no pós-fordismo, a força de trabalho buscada, além da capacidade de adaptação e de criatividade, constitui-se como "uma força de trabalho polioperativa que sabe 
'ler' o fluxo de informações, que sabe trabalhar comunicando" (MARAZZI, 2009a, p. 18).

De maneira a sistematizar esse processo, a economista Antonella Corsani (2003) afirma que:

A passagem do fordismo ao pós-fordismo pode ser lida como a passagem de uma lógica da reprodução a uma lógica da inovação, de um regime de repetição a um regime da invenção. (CORSANI, 2003, p.15)

Conforme a autora, o conjunto dessas condições é que evidencia aquilo que chamamos de capitalismo cognitivo.

Aceitando a hipótese de que o capitalismo cognitivo opera sob o duplo eixo da inovação e da invenção, é importante evidenciar que o capitalismo industrial também mobilizava esses valores; entretanto, eles apareciam como exceção. No fordismo,

[...] a valorização repousava essencialmente sobre o domínio do tempo de reprodução de mercadorias padronizadas, produzidas com tecnologias mecânicas. (CORSANI, 2003, p. 17)

No capitalismo cognitivo, o que antes era exceção agora se torna regra, pois a valorização não está ligada à reprodução mecânica, mas ao conhecimento. Tal como argumenta Corsani, o que favoreceu essa dinâmica inovadora foi o paradigma tecnológico, ou seja, a busca incessante por progressos técnicos e questionamento de problemas específicos da vida contemporânea.

0 conhecimento assume o lugar de vetor das inovações e das dinâmicas produtivas do capitalismo cognitivo (LAZZARATO, 2003). Importa destacar, conforme os autores citados, que o conhecimento se posiciona como um recurso e não como um produto ou uma mercadoria.

É por isso que se pode falar a justo título de produção de conhecimentos por conhecimentos, o que traduz e denota a ideia de que se passa de um regime de reprodução a um regime de inovação. (CORSANI, 2003, p. 27).

Procurando explicar essa relação, que não faz do conhecimento uma mercadoria como as outras, Lazzarato (2003) estabelece uma diferenciação entre a fábrica de alfinetes de Adam Smith e a de livros de Gabriel Tarde. 0 sociólogo argumenta que a principal diferença está na ordem do valor: enquanto o alfinete teria apenas o valor material, o livro teria um duplo valor: material e imaterial. Diferentemente do alfınete, no livro, "o consumo não é destrutivo, mas criador de outros conhecimentos. Consumo e produção coincidem na produção de livros" (LAZZARATO, 2003, p. 69).

Considerando que no capitalismo cognitivo a lógica da inovação é privilegiada, o que sabemos não significa o fim dos dispositivos disciplinares; neste momento, cabe interrogar pelos regimes de trabalho do capitalismo cognitivo. Alguns autores, como Vercellone (2009), Vercellone e Negri (2007) e Negri (2008), postulam que essa configuração capitalista expõe uma crise das clássicas noções da economia política, que são o trabalho, o capital e o valor.

No que concerne ao trabalho, o crescimento da sua dimensão imaterial e cognitiva marca, sem dúvida, uma crise de sua medida. 0 trabalho cognitivo, com efeito, se apresenta, por essência, como a combinação complexa de um trabalho intelectual de reflexão, de acerto, de partilha e de elaboração de saberes que se efetua tanto em quantidade como no quadro do trabalho imediato de produção. Nesse quadro, o trabalho mensurado com o tempo passado e certificado na empresa frequentemente não é mais do que uma fração do tempo social efetivo do trabalho (VERCELLONE, 2009, p. 12).

A argumentação desenvolvida pelo autor expõe outra importante nuance do capitalismo cognitivo que é a alteração das relações entre 
capital e trabalho. Conforme Vercellone e Negri (2007), tal alteração pode ser lida como uma transformação radical, visto que:

Ela diz respeito, de uma maneira indissociável, ao modo de produção, à composição de classe sobre o qual se apóia a valorização do capital e, enfım, às formas de distribuição do rendimento entre salário, renda e lucro. (VERCELLONE; NEGRI, 2007, p. 1)

Os autores retomam a ideia de que a crise entre o operário-massa e o trabalho cognitivo, característica da atualidade, é comparável à crise dos anos 1930 que se desencadeou no modo de organização fordista. Entretanto, ao realizar a leitura das novas relações entre capital e trabalho, os autores destacam dois processos.

0 primeiro é que, no capitalismo cognitivo, "o motor essencial da emergência de uma economia fundada no conhecimento se encontra na potência do trabalho vivo" (VERCELLONE; NEGRI, 2007, p. 2). Servindo-se de uma argumentação neomarxiana, os autores procuram mostrar como o trabalho humano do novo capitalismo, ao tornar-se imaterial, não é submetido e absorvido pelas condições disciplinares do regime da fábrica (trabalho morto). Antes disso, o trabalho não era separado do conhecimento, não era cristalizado em esforço muscular. Ele permanecia vivo, visto que, mesmo diante de um conjunto de ferramentas técnicas, é a cognição humana que mobiliza a rede.

0 segundo argumento, decorrente do primeiro, é que não são as tecnologias os elementos determinantes da mutação do trabalho.

0 elemento determinante da atual mutação do trabalho não pode ser explicado sobre a base de um determinismo tecnológico fundado sobre o lugar central das tecnologias da informação e da comunicação. (VERCELLONE; NEGRI, 2007, p. 2)

Seguindo a argumentação dos autores, aqueles que defendem a primazia da tecnologia estão esquecendo que são os saberes vivos que a mobilizam:

uma vez que é o conhecimento que governa o tratamento da informação informação que será, de outra forma, um recurso estéril como é o capital sem trabalho. (VERCELLONE, NEGRI, 2007, p.2)

A partir desse entendimento, os autores apontam algumas das principais características das novas relações entre capital e trabalho. De forma sintética, indicam o privilégio do trabalho vivo nas condições de trabalho contemporâneas, a desestabilização do modelo da fábrica, com a consequente emergência da forma empresa, e "a passagem de uma divisão taylorista a uma divisão cognitiva do trabalho" (VERCELLONE; NEGRI, 2007, p. 4). Assim, a força de trabalho não é mais alicerçada no controle do tempo e do espaço, mas baseada nos saberes e na "capacidade de aprendizagem, de inovação e de adaptação a uma dinâmica de mudança contínua" (VERCELLONE; NEGRI, 2007, p. 5). Os princípios científicos de organização da produção, portanto, assumem novas configurações.

Porém, tudo muda quando o trabalho, tornando-se sempre mais imaterial e cognitivo, não pode mais ser reduzido a um simples consumo de energia efetuado em um dado tempo. 0 velho dilema concernente ao controle do trabalho reaparece em formas novas.

O capital não somente é tornado dependente do saber dos assalariados, mas deve obter uma mobilização e uma implicação ativa do conjunto dos conhecimentos e dos tempos de vida dos assalariados. (VERCELLONE; NEGRI, 2007, p. 6)

A imaterialização do trabalho produz novas estratégias a respeito das subjetividades dos trabalhadores. Na medida em que não é mais a fábrica o modelo de regulação da sociedade, é a empresa que assume o status de 
modo de regulação dessa sociedade (DELEUZE, 1992). Talvez a grande diferença entre ambos os espaços, conforme Moulier-Boutang (2003), seja que a fábrica operava a partir da limitação territorial, pelo confınamento, enquanto a empresa, pela sua fluidez, espalha-se por toda a sociedade.

A empresa não está mais na empresa, ela está em toda parte, imiscuindo-se graças à penetração mercantil no conjunto da vida e criando assim um novo espaço, o 'território produtivo'. (MOULIERBOUTANG, 2003, p. 39)

Dessa forma, não mais se visibiliza uma "sociedade-fábrica industrial, mas a sociedadeempresa” (p. 41).

Essa empresa-sociedade sofistica as tecnologias de poder na contemporaneidade, não apenas sobre as subjetividades, mas sobre todo o conjunto da sociedade. 0 italiano Christian Marazzi (2009b) argumenta que os novos arranjos de poder dessa sociedade poderiam ser caracterizados como biocapitalismo, um capitalismo da inovação permanente e da flexibilidade.

0 biocapitalismo põe a vida no centro do crescimento econômico. A própria vida, a vida nua, se torna fonte de valor, ou melhor, um mais-valor absoluto que não é reconhecido pelo capital e, portanto, não é pago. (MARAZZI, 2009b, p. 11)

Para finalizar, reiteramos que o presente ensaio pretendeu constituir um diagnóstico preliminar das políticas de escolarização e governamentalidade produzidas nas tramas políticas e econômicas do estágio atual do desenvolvimento capitalista. Partindo de uma revisão dos modos de constituição das políticas de escolarização produzidas pelo estado moderno, objetivamos, desde uma inspiração nos estudos foucaultianos produzidos no final da década de 1970, caracterizar as diferentes estratégias reguladoras dos processos de escolarização em massa produzidos desde o século XVIII e diagnosticar os múltiplos deslocamentos nessas pautas políticas na Contemporaneidade.

Entendemos que as condições do capitalismo cognitivo, tal como esse cenário tem sido nomeado pelos economistas neomarxistas italianos, sugerem um cenário no qual o conhecimento assume o lugar de vetor das inovações e das dinâmicas produtivas, desestabilizando o modelo da fábrica e imaterializando as relações de trabalho. Inúmeras problematizações ainda precisam ser produzidas sobre esses cenários, sobretudo no que se refere às concepções de conhecimento, às relações entre trabalho e educação e aos sentidos das novas políticas curriculares mobilizadas na agenda global.

De toda forma, é possível afirmar que as políticas de escolarização passam a ser movidas por tecnologias otimizadoras que privilegiam conduzir os sujeitos escolares a estágios elevados de desempenho, assim como propõem a qualificação de suas performances nas tramas do contemporâneo. Tal diagnóstico, com seus diferenciados objetos analíticos e abordagens teóricas, pode ser ponto de partida para ressignificarmos as pautas investigativas dos estudos críticos em educação. 


\section{Referências}

ALVAREZ-URIA, Fernando. A escola e o espírito do capitalismo. In: COSTA, Marisa V. (Org.). Escola básica na virada do século: Cultura, política e currículo. 3. ed. São Paulo: Cortez, 2002, p. 131-144.

BELL, Daniel. Advento da sociedade pós-industrial: uma tentativa de previsão social. São Paulo: Cultrix, 1977.

CAMBI, Franco. História da pedagogia. São Paulo: Ed. UNESP, 1999.

CASTEL, Robert. A insegurança social: 0 que é ser protegido? Petrópolis: Vozes, 2004.

0 futuro da autonomia e a construção de uma sociedade de indivíduos: uma leitura sociológica. In: NEUTZLING, Inácio; BINGEMER, Maria Clara; YUNES, Eliana (Orgs.). Futuro da autonomia: Uma sociedade de indivíduos? Rio de Janeiro: Editora da PUC-Rio; São Leopoldo: Editora Unisinos, 2009, p. 107-119.

CORSANI, Antonella. Elementos de uma ruptura: a hipótese do capitalismo cognitivo. In: COCCO, Giuseppe; GALVÃO, Alexander Patez; SILVA, Geraldo; (Orgs.). Capitalismo cognitivo: Trabalho, redes e inovação. Rio de Janeiro: DP\&A, 2003, p. 15-32.

DEAN, Mitchell. Governmentality: power and rule in modern society. London: Sage, 1999.

DELEUZE, Gilles. Política. In: DELEUZE, Gilles. Conversações. São Paulo: Ed. 34, 1992, p. 209-226.

FIMYAR, Olena. Governamentalidade como ferramenta conceitual na pesquisa de políticas educacionais. Educação e Realidade, v. 34, n. 2, p. $35-56,2009$.

FOUCAULT, Michel. Vigiar e punir. Petrópolis: Vozes, 1989.

Segurança, território, população. São Paulo: Martins Fontes, 2008a.

0 nascimento da biopolítica. São Paulo: Martins Fontes, 2008b.

HAMILTON, David. 0 revivescimento da aprendizagem? Educação e Sociedade, n. 78, p. 187-198, 2002.

HARVEY, David. Condição pós-moderna: uma pesquisa sobre as origens da mudança cultural. 12. ed. São Paulo: Loyola, 2003.

JÓDAR, Francisco; GÓMEZ, Lúcia. Educación posdisciplinaria, formación de nuevas subjetividades y gubernamentalidad neoliberal: herramientas conceptuales para um analisis del presente. Revista Mexicana de Investigación Educativa, n. 32, p. 381-404, 2007.

LAZZARATO, Maurízio. Trabalho e capital na produção de conhecimentos: uma leitura através da obra de Gabriel Tarde. In: COCCO, Giuseppe; GALVÃ0, Alexander Patez; SILVA, Geraldo. (Orgs.). Capitalismo cognitivo: trabalho, redes e inovação. Rio de Janeiro: DP\&A, 2003, p. 61-82.

As revoluções do capitalismo. Rio de Janeiro: Civilização Brasileira, 2006.

LYON, David. Pós-modernidade. São Paulo: Paulus, 1998.

MARAZZI, Christian. 0 lugar das meias: a virada linguística da economia e seus efeitos sobre a política. Rio de Janeiro: Civilização Brasileira, 2009a.

Biocapitalismo: a vida no centro do crescimento econômico. IHU On Line, n. 301, p. 10-11, 2009b.

MOULIER-BOUTANG, Yann. 0 território e as políticas de controle do trabalho no capitalismo cognitivo. In: COCCO, Giuseppe; GALVÃO, Alexander; SILVA, Geraldo; (Orgs.). Capitalismo cognitivo: trabalho, redes e inovação. Rio de Janeiro: DP\&A, 2003, p. 33-60.

NARODOWSKI, Mariano. Después de clase: desencantos y desafios de la escuela atual. Buenos Aires: Novedades Educativas, 1999.

BRAILOVSKI, Daniel. La cuestión del fin de la razón de estado en la historia de la escolarización. In: NARODOWSKI, Mariano; BRAlLOVSKI, Daniel (Orgs.). Dolor de escuela. Buenos Aires: Prometeo Libros, 2006, p. 61-80. 
NEGRI, Antonio. Reddito di cittaddinanza come dispositivo costituente. Posse: política, filosofia, moltitudini, julho, 2008. Disponível em: <www.posseweb.net/spip.php?article190>. Acesso em: 24 set. 2009.

NOGUERA, Carlos. La gubernamentalidad en los cursos del profesor Foucault. Educação e Realidade, v. 34, n. 2, p. 21-34, 2009.

Ó, Jorge Ramos do. A governamentalidade e história da escola moderna: outras conexões investigativas. Educação e Realidade, v. 34, n. 2, p. 97-117, 2009.

POPKEWITZ, Thomas. Reforma, conhecimento pedagógico e administração social da individualidade: a educação escolar como efeito de poder. In: IMBERNÓN, Francisco (Org.). A educação no século XXI: os desafios do futuro imediato. Porto Alegre: Artmed, 2000, p. 141-170.

SANSON, César. A produção biopolítica é constitutiva ao capitalismo cognitivo. Liinc em Revista, v. 5, n. 2, p. 206-214, 2009.

SARAIVA, Karla; VEIGA-NETO, Alfredo. Modernidade líquida, capitalismo cognitivo e educação contemporânea. Educação e Realidade, v. 34, n. 2, p. 187-201, 2009.

SENNETT, Richard. A corrosão do caráter: as consequências pessoais do trabalho no novo capitalismo. 5. ed. Rio de Janeiro: Record, 2001.

. A cultura do novo capitalismo. 2. ed. São Paulo: Record, 2008.

SILVA, Roberto Rafael Dias da. Universitários S/A: estudantes universitários nas tramas de Vestibular/ZH. Dissertação (Mestrado em Educação) - Universidade do Vale do Rio dos Sinos, São Leopoldo, 2008.

. A universidade e a formação de professores na contemporaneidade: contribuições para uma crítica política. In: BENINCÁ, Dirceu (Org.). Universidade e suas fronteiras. São Paulo: Outras Expressões, 2011a, p. 149-169.

A constituição da docência no ensino médio no Brasil contemporâneo: uma analítica de governo. Tese (Doutorado em Educação) - Universidade do Vale do Rio dos Sinos, São Leopoldo, 2011b.

VARELA, Julia. Categorias espaço-temporais e socialização escolar: do individualismo ao narcisismo. In: COSTA, Marisa V. (Org.). Escola básica na virada do século: cultura, política e currículo. $3^{\mathrm{a}}$ ed. São Paulo: Cortez, 2002, p. 73-106.

VEIGA-NETO, Alfredo. Foucault \& a educação. 2. ed. Belo Horizonte: Autêntica, 2005.

Na oficina de Foucault. In: KOHAN, Walter Omar; GONDRA, José (Org.). Foucault 80 anos. Belo Horizonte: Autêntica, 2006, p. $79-91$.

VERCELLONE, Carlo; NEGRI, Antonio. II rapporto capitale/lavoro nel capitalismo cognitivo. Posse: política, filosofia, moltitudini, nov. 2007. Disponível em: <www.posseweb.net/spip.php?article17>. Acesso em: 24 set. 2009.

VERCELLONE, Carlo. A crise e os contornos de um "socialismo totalitário do capital". IHU On Line, n. 301, p. 12-18, 2009.

Recebido em:05.08.2012

Aprovado em:11.03.2013

Roberto Rafael Dias da Silva é mestre e doutor em Educação pela Universidade do Vale do Rio dos Sinos - UNISINOS. Atualmente é Professor Adjunto na Área de Fundamentos da Educação na Universidade Federal da Fronteira Sul - UFFS. 